Please do not remove this page

RMIT

UNIVERSITY

\title{
Fostering innovation through cultural change
}

Leong, Julia; Anderson, Craig

https://researchrepository.rmit.edu.au/esploro/outputs/9921859390701341/filesAndLinks?institution=61RMIT_INST\&index=null

Leong, J., \& Anderson, C. (2012). Fostering innovation through cultural change. Library Management, 33(8), 490-497. https://doi.org/10.1108/01435121211279858

Published Version: https://doi.org/10.1108/01435121211279858

Repository homepage: https://researchrepository.rmit.edu.au

(c) 2012 Emerald Group Publishing Limited.

Downloaded On 2023/04/26 21:31:58 +1000

Please do not remove this page 
Thank you for downloading this document from the RMIT Research Repository.

The RMIT Research Repository is an open access database showcasing the research outputs of RMIT University researchers.

RMIT Research Repository: http://researchbank.rmit.edu.au/

\section{Citation:}

Leong, J and Anderson, C 2012, 'Fostering innovation through cultural change', Library Management, vol. 33, no. 8, pp. 490-497.

See this record in the RMIT Research Repository at:

http://researchbank.rmit.edu.au/view/rmit:17897

Version: Submitted Version

Copyright Statement: (c) 2012 Emerald Group Publishing Limited.

Link to Published Version: http://dx.doi.org/10.1108/01435121211279858 


\title{
Fostering innovation through cultural change
}

\author{
Julia Leong and Craig Anderson \\ RMIT University, Australia \\ julia.leong@rmit.edu.au, craig.anderson@rmit.edu.au
}

\section{Structured Abstract:}

\section{Purpose}

The paper demonstrates a range of approaches to promoting innovative thought and action which can be applied in a variety of organizational contexts.

\section{Design/methodologylapproach \\ It describes strategies adopted by one large academic library which sought to increase employee engagement and levels of innovation. Included is the background situation, a description of cultural change activities undertaken, information on provision of a suite of practical innovation process tools, and reference to relevant literature.}

\section{Findings}

The leadership framework of RMIT University, and associated developmental opportunities, benefit the library which also offers a tailored developmental programme for its leadership group. Specific purpose groups are used in the library to build capacity and promote cultural change. The library promotes involvement in professional associations and supports innovation through the provision of practical tools and techniques which can be used by staff at all levels. Building an innovative culture is challenging in a large organization, but sustaining effort over time, utilizing a variety of approaches and developing positive sub-cultures among motivated staff have been found to be beneficial.

\section{Originality/value}

By describing strategies to promote an innovative organizational culture, this article has originality. Most related library literature addresses specific innovations.

Keywords:

Innovation, Organizational culture, Academic libraries

Article Classification:

Case study

\section{Introduction}

Innovation is in vogue, but we must acknowledge that it is not new. Throughout history people and organizations have faced the need to change in order to survive and thrive. Academic libraries today face the same challenge. As many authors have made the case that change is a current imperative (Bryson, 2006; Salama, 2011; Wulfen, 2011), it is not our intention to restate their arguments here, but to take the ongoing need to innovate as a given. The purpose of this paper is to provide a range of approaches to the promotion of innovative thought and action which can be applied in a variety of organizational contexts. It describes strategies adopted by the RMIT University Library over the last five years which were designed to increase employee engagement and levels of innovation. Included is an overview of the background situation, a description of cultural change activities undertaken, and information on the recent development of a suite of practical innovation process tools.

Rowley (2011) argues in favour of libraries developing an holistic and strategic approach to their innovation activities and discusses a number of facets which may be included in an innovation strategy. These include: innovation capabilities and culture; a portfolio of varying types of innovation; innovation processes; innovation and leadership; innovative and creative teams; open innovation and collaboration; and, user engagement in innovation. The RMIT University Library approach has incorporated a number of these facets with a focus on changing organizational culture through leadership development, specific purpose working groups, team development for all staff, and developing processes to support innovation. Tidd and Bessant (2009, pp. 68-76) raise the question as to whether innovation can be managed, concluding that the development of an integrated set of routines improves likelihood of success. Papers such as that by Rowley (2011) and innovation models such as those offered by Ginzburg, Higgins and Lichtenstein (2007), Jones and Samalionis (2008) and Tidd and Bessant (2009) are a good place to start when considering what practical actions to take to improve innovation levels. 
Descriptions of innovation models can be quite complex and successful outcomes involve more than following a series of steps rigorously. As Soken (2008) states:

Innovation differs from development efforts because it requires a degree of uncertainty and challenges to the status quo. Often, processes that drive improvement require repeatability and minimize variability. Innovation is about increasing variability and encouraging expansive and divergent thinking. Rather than the "drive for results" leadership that seeks quick alignment and efficient execution, innovation leaders ask people to look at problems from different perspectives, take unfamiliar positions, identify and test their assumptions, and take risks. Such leaders make room for experimentation, mistakes, and failures while requiring focus and discipline.

From interviews with university librarians at six institutions, to discover their perspectives on innovation in academic libraries, Jantz (2012) found that leadership and management can foster innovation in a library, but factors such as organizational size and complexity and environmental factors also play a part.

Additionally the norms of the profession may in part push against the ability to innovate. The conflict between efficiency and generation of new ideas was raised, as was fear of risk-taking (Jantz, 2012, p. 7). Leaders need to balance the maintenance of 'order' which is required for efficiency, with the development of 'diversity' to generate innovation to meet future demands (Salama, 2011). Innovation processes and management styles need to be synchronized. Salama (2011, p. 3) sees a close relationship between entrepreneurship and leadership styles and learning cultures. She says, "A management culture based on traditional values of obedience and bureaucracy is not entrepreneurial" and must be changed to one that welcomes ideas from those working in the lower levels of the hierarchy and encourages working teams to learn from each other (Salama, 2011, p. 2).

When seeking to increase levels of innovation, it may be necessary to consider the impact of organizational and managerial cultures on employee engagement levels. Ogbonna (1992) says that while there is no consensus on the definition of culture, researchers agree that culture can have a pervasive effect on organizational outcomes. The terms 'organizational culture' and 'corporate culture' are sometimes used interchangeably and sometimes distinguished from each other. Oliver (2011) sees organizational culture as shaped by national, occupational and corporate cultures, the latter being the "most susceptible to change" (Oliver, 2011, p. 111). She says corporate culture can be observed through such things as leadership/management style, stories that circulate in the workplace, in-house specialist language, dress codes, and corporate branding (2011, p. 121). Somewhat variably, Salama (2011, p. 21) sees corporate culture as created by founders' and leaders' values, national values, and the type of industry. However in Creating and Re-Creating Corporate Entrepreneurial Culture she limits her investigation of corporate culture change to:

The analysis of how the organization goes through the process of modifying some of its values, beliefs and assumptions and ultimately altering how managers are expected to behave: from bureaucracy towards entrepreneurism, from inertia towards renewal and internal innovation. (Salama, 2011, p. 23)

The above quotation captures much of the intent of the RMIT University Library change processes as illustrated by the following case study, although the steps taken are not identical to those in Salama's model (Salama, 2011, pp. 55-8).

\section{The RMIT University and Library context}

RMIT University is a large tertiary educational institution located in Melbourne Australia. The University has more than 75,000 students including approximately 16,000 students attending an off-shore campus or studying with partner institutions. The Australian tertiary education sector is undergoing rapid change, particularly in response to various Federal Government initiatives such as the Bradley Report (Bradley et al., 2008, p. 271) and the change to a "demand-driven" system (Australia. Department of Education,

Employment and Workplace Relations, 2011) as well a general tightening of funding in the tertiary education sector. These pressures have resulted in a need for more innovation in the provision of tertiary education and improved leadership to bring this change. RMIT University has a deliberate and distinctive focus on cultural change and support for leadership and has invested in a series of initiatives to support and improve leadership capabilities including the ability to innovate. This programme, leadRMIT, comprises an extensive suite of activities and training both online and face-to-face.

The well documented need for change in the information industry (Bryson, 2006; Pugh, 2007; Woodward, 2009) provided a backdrop and encouragement to library staff to innovate and change. A more direct and obvious indicator of the changing role of the library was a steady drop in one of the traditional forms of 
service, loans of books. In spite of growing student numbers, loans of physical materials had been decreasing for several years. In 2000, 55,500 students borrowed just over 600,000 items - but by 2010 , in spite of a $33 \%$ increase in student numbers to 73,900 , there was a fall in the absolute number of loans to 411,000 - a decrease from 10.8 loans per student to 5.7 loans per student. Other indicators of library use also changed - there was shift from 'long' (generally in-depth) reference questions to shorter and more directional type inquiries.

Engaged staff and confident leaders were needed to adapt to changed patterns of use, to meet changing user expectations, and to envisage and implement new approaches to service, resource and access delivery. However, input from a broad leadership group formed inside the library and an organization-wide climate survey, which provided results at unit level, indicated that library staff engagement levels were below desirable levels.

The remainder of the paper describes actions taken to enhance employee engagement and innovative potential through leadership development, cross unit work experience, formation of specific purpose work groups, and development of clearer innovation processes.

\section{Cultural change in the Library}

\subsection{Leadership development}

Jantz (2012, p. 6) discusses the need for leadership as a key component in innovation and the RMIT University Library has been working to strengthen its leadership capacity. Since 2008 the library has recognised 18 to 20 staff as a 'leadership' group. The group identified elements of the existing organizational culture which were felt to be negative and also recognized positive elements (Leong and Vaughan, 2010). Desirable changes to the culture were also identified and leadership development was provided to equip managers to support the agreed direction. This professional development included many of the group participating in the leadRMIT courses which involved several full-day sessions with expert external facilitators over a few months. Use of the Hay Group inventories, such as the Inventory of Leadership Skills and the Emotional Competency Inventory, gave managers insights into their approaches and the leadership styles which are supportive of staff engagement. Additionally, the library arranged sessions to address specific people management skill needs. After the initial batch of training, a Round Table was formed as an ongoing opportunity to share insights gained from professional reading, conferences, and other sources, and to discuss leadership and management issues.

\subsection{Cross unit work}

As in any large library there is tendency towards a culture of specialization, or in a more negative vein "silos". Typically this means that staff in the loans area (for instance) tend not to have any experience in technical service areas, and those in technical service areas tend not to have experience in working with library users. In order to overcome this "silo effect" cross unit project work opportunities have been increased and, in 2008, a new system of cross-unit work experience (CUEs) was created by a working party and mediated by the staff development librarian. Under this system managers were invited to create training opportunities which were placed on an internal register, and staff were invited to express interest in these opportunities.

Four categories of CUEs were defined and these continue to operate. They are:

- Half day - 3 day block (short): primarily aimed at staff in their first two years of employment to enhance cross unit cooperation.

- $\quad$ Shadowing (short): providing a short term opportunity to gain insight into another's work, often where actually doing the work is not feasible.

- 1 day week for 6 months (long): promoting multi-skilling and workforce flexibility.

- $\quad$ Full time immersion (4-8 weeks) (long): providing an opportunity to enhance multi-skilling and workforce flexibility.

While there has not been formal assessment of the CUE scheme, evaluation forms provided by participants, anecdotal feedback, and the on-going commitment of managers to create and support the scheme has indicated that the experience is valuable for the staff member, and productive from the manager's perspective.

\subsection{Specific purpose working groups}

Several specific working groups were also created to encourage more open and innovative approaches to the changing environment. These included the New Professionals Group and the Innovative Librarians. The New Professionals Group was created with the intention of entrenching a positive organizational culture and developing organizational savvy and capability. It was hoped that the formation of this group would support the less experienced professionals to act as change agents (Leong and Vaughan, 2010), but while the group did appear to have some success in this direction, Lankes (2010, pp. 52, 72) warns against using the least experienced staff as the dominant lever for innovation. The Innovative Librarians or "Innovatives" group was 
focussed on exploring new technologies (Badham et al., 2011), communicating these to staff, and making recommendations as to how these might be used. One of the challenges in terms of the impact of this group was that the members were in relatively low-influence positions in terms of traditional hierarchy and they often lacked strong advocacy skills and confidence. More recently the group has begun to explicitly to address that need.

\subsection{Promotion of involvement in professional associations}

The University Librarian promotes involvement in professional associations and leads by example. The largest city-based library is provided as a free venue for association activities regularly. There is a good level of staff involvement in professional activities including attending and presenting at meetings and conferences, writing news items and articles, and undertaking study tours.

\section{Innovation and all staff}

To maximise innovative activity requires buy-in which extends beyond leaders and select individuals.

Whereas innovation is often seen as the province of specialists in R\&D, marketing, design or IT, the underlying creative skills and problem-solving abilities are possessed by everyone. If mechanisms can be found to focus such abilities on a regular basis across the entire company, the resulting innovative potential is enormous. Although each individual may only be able to develop limited, incremental innovations, the sum of these efforts can have farreaching impact. (Tidd and Bessant, 2009, p. 115)

In recognition of this there is current work across all units and levels of staff utilizing Team Management Profiles, a Team Management Systems (TMS) instrument (Team Management Systems, 2009). Staff complete profiles online and then participate in workshops: to gain an understanding of the TMS approach; to gain insights to and appreciation of diverse approaches to work; to assess team strengths weaknesses and priorities; and to take steps to enhance effectiveness. While internal TMS workshop facilitators do not place a major focus on the link between team health and innovation, Team Management Profiles and workshop experiences lay a foundation for improving innovation levels by identifying individual work preferences, affirming the value of each person's unique contribution, increasing understanding between individuals which may increase levels of trust, and opening up conversations on new ways of thinking about work.

To make explicit the desirability of greater levels of innovation, a simple Innovation Process Model has been created and this links to the team development work by utilizing colours in a way consistent with TMS use of them. A number of models exist, but in their detail many are geared to product development and sales. An example of a model designed for innovation in services is IDEO's five-stage framework: develop insight about the market; create radical value propositions; explore creative service models; bend the rules of delivery; and iteratively pilot and refine the new service (Jones and Samalionis, 2008, p. 22). Ginzburg, Higgins, and Lichtenstein (2007) offer a service development model which is appropriate in a library context and which groups fifteen steps under three headings - generate, develop and deploy. The wording in the RMIT University Library model is similarly straightforward, matching the practical bent of most Australian library staff. In itself the model is far from novel, but along with library-wide TMS work, it provides a basis for a common language across units and levels of staff and a basis for skill development in support of innovation. Tidd and Bessant (2009, p. 74) argue that "successful innovation management is primarily about building and improving effective routines." Each organization has different routines or ways of doing things (Tidd and Bessant, 2009, p. 71). The library is seeking to create new routines which support innovative thought and action.

\subsection{Developing practical techniques and providing training}

A short-term working party has selected and described idea generation techniques considered appropriate to the RMIT University Library while taking into consideration the fairly even balance between introverts and extroverts among staff. Also, this group has been developing approaches for strengthening ideas, both to avoid "idea assassination" from ideas being recommended without adequate thought, and also to ensure ideas are as well presented as possible before formal approvals are sought. This necessitated clarifying criteria used to decide whether or not to accept and implement suggestions, and reaching agreement on a template for making suggestions and providing feedback. To ensure this work is not isolated from reality, techniques are being trialled in current library projects.

Whilst experienced managers may see the above as common sense and unnecessary, not all staff understand the criteria used by decision makers, or why their seemingly good ideas are apparently ignored or rejected at times. By making the process more explicit and providing techniques for all to use it is hoped to see suggestions made consistently in a way which allows quicker assessment and decision-making. Making appropriate resources available should also result in people putting more thought into initial ideas and having 
a better grasp of the bigger picture decision-makers must consider. In addition to providing descriptions of techniques and processes for making suggestions, staff training and mentoring is valuable. Tidd and Bessant (2009, p. 73) provide a table of nine core abilities needed in managing innovation and this is useful for assessing current strengths and weaknesses and prioritizing developmental initiatives. In terms of their list, the RMIT University Library is working on "Developing the organization" through developing processes including the way we go about "Choosing" or exploring and selecting appropriate actions in response to problems and challenges.

\section{Outcomes}

The need for libraries to embrace innovation is clear; however, the capacity of each library to do so varies. In seeking to deepen capacity at the RMIT University Library, several strategies have been employed. These include: leadership development to enhance the knowledge, motivation, and skills of managers to engage staff; cross unit project groups and work experience; specific purpose working groups; promotion of involvement in professional associations; team development; adoption of an innovation process model; and provision of practical innovation techniques. Outcomes for each strategy need separate assessment. A management skills audit undertaken in late 2010 and early 2011 affirmed significant progress in overall confidence levels of managers regarding their people management skills. The impact of participation in cross unit projects and cross unit work experience has not been fully assessed, but anecdotal evidence suggests these have been a positive force. Involvement in specific purpose groups has clearly had positive impact on participants, but it is difficult to quantify the long-term benefit to the organization as a whole. Team development and innovation process work is recent and the impact of each has not yet been evaluated. Additionally in the future, is a repeat organizational climate survey which will determine whether the engagement levels have risen among library staff. In summary, the strategies which have been adopted have been worthwhile, but this remains a work in progress.

\section{Practical implications}

Many factors impact on the innovative capacity of a library. Organizational culture and leadership styles are among those factors. This paper has offered a case study of a large library where innovative strength and staff engagement were examined, needed changes were recognized and follow through involved leadership, individual and team based development. The paper features a range of specific approaches including addressing innovation processes. Sustaining effort over time, utilizing a variety of approaches and developing positive sub-cultures among motivated staff have been found to be beneficial. Other libraries can benefit from consulting the pertinent literature identified in the Introduction and applying approaches which are suitable for their particular context.

\section{References}

Australia. Department of Education, Employment and Workplace Relations (2011), Fact sheet: demand driven funding for undergraduate student places, available at: http://www.deewr.gov.au/HigherEducation/Resources/Documents/DemandDrivenSystem.pdf (accessed 15 March 2012).

Badham, T., Chivers, M., Frerichs, W. and Dart, S. (2011), "Innovative librarians: harnessing passion and involvement for library metamorphosis", in ALIA 5th New Librarians Symposium 2011, Perth, Australia, 16-16 September, ALIA, available at: http://conferences.alia.org.au/nls5/papers/Sian Dart.pdf (accessed 5 July 2012).

Bradley, D., Noonan, P., Nugent, H. and Scales, B. (2008), Review of Australian Higher Education: Final Report, Australian Government, Canberra, available at: http://www.deewr.gov.au/HigherEducation/Review/Documents/PDF/Higher\%20Education\%20Revie w one\%20document 02.pdf (accessed 15 March 2012).

Bryson, J. (2006), Managing Information Services: A Transformational Approach, Ashgate, Aldershot, Hampshire.

Ginzburg, I., Higgins, A. and Lichtenstein, Y. (2007), "Looking for the locus of innovation in new service development", in Proceedings of the 40th Hawaii International Conference on System Sciences 2007, IEEE, available at: http://ieeexplore.ieee.org/xpls/abs all.jsp?arnumber=4076847 (accessed 28 September 2011).

Jantz, R.C. (2012), "Innovation in academic libraries: an analysis of university librarians' perspectives", Library \& Information Science Research, Vol. 34 No. 1, pp. 3-12, available at: http://www.sciencedirect.com/science/article/pii/S074081881100096X (accessed 19 January 2012).

Jones, M. and Samalionis, F. (2008), "From small ideas to radical service innovation", Design Management Review, Vol. 19 No. 1, p. 20, available at: http://www.dmi.org/dmi/html/publications/news/ebulletin/08191JON20.pdf (accessed 28 September 2011). 
Lankes, R.D. (2010), "Innovators wanted: no experience necessary?", in Walter, S. and Williams, K. (Eds), The Expert Library: Staffing, Sustaining and Advancing the Academic Library in the 21st Century, Association of College and Research Libraries, Chicago.

Leong, J. and Vaughan, M. (2010), "Preparing new librarians for career and organizational impact", Library Management, Vol. 31 No. 8/9, pp. 635-44, available at: http://dx.doi.org/10.1108/01435121011093405 (accessed 5 Juy 2012).

Ogbonna, E. (1992), "Managing organisational culture: fantasy or reality?", Human Resources Management Journal, Vol. 3 No. 2, pp. 42-54, available at: http://onlinelibrary.wiley.com/doi/10.1111/.17488583.1992.tb00309.x/pdf (accessed 5 July 2012).

Oliver, G. (2011), Organisational Culture for Information Managers, Chandos Information Professional Series, Chandos Publishing, Oxford.

Pugh, L. (2007), Change Management in Information Services, 2nd edn, Ashgate, Aldershot, Hampshire.

Rowley, J. (2011), "Should your library have an innovation strategy?", Library Management, Vol. 32 No. 4/5, pp. 251-65, available at: http://www.emeraldinsight.com/journals.htm?articleid=1926024\&show=abstract (accessed 12 January 2012).

Salama, A. (2011), Creating and Re-creating Corporate Entrepreneurial Culture, Gower, Farnham, Surrey.

Soken, N. and Barnes, B.K. (2008), "Innovation journey", Leadership Excellence, Vol. 25 No. 9, p. 5, available at: http://search.proquest.com/docview/204617669/abstract (accessed 12 January 2012).

Team Management Systems (2009), Team Management Profile, TMS, available at: http://www.tmsoz.com/team-management-profile (accessed 26 March).

Tidd, J. and Bessant, J.R. (2009), Managing Innovation: Integrating Technological, Market and Organizational Change, 4th edn, Wiley, Chichester, England.

Woodward, J. (2009), Creating the Customer-Driven Academic Library, American Library Association, Chicago.

Wulfen, G.v. (2011), Creating Innovative Products and Services, Gower, Farnham, Surrey. 